\title{
Replication of Pressure Swirl Atomizer by 3D Printing and Influence of Surface Roughness on the Atomization Quality
}

\author{
Ondřej Cejpek ${ }^{1, *}$, Milan Malý ${ }^{1}$, Miloslav Bělka ${ }^{1}$, and Jan Jedelský ${ }^{1}$ \\ ${ }^{1}$ Faculty of mechanical engineering, Energy institute, 61669 Brno, Czech Republic
}

\begin{abstract}
The replication of atomizers by $3 \mathrm{D}$ printing technology is a new approach of producing the pressure swirl atomizers. The surface roughness of $3 \mathrm{D}$ printed products and manufacturing accuracy of the 3D printing process influence the atomization of the liquid. The high-speed visualization of a spray, produced by scaled 3D printed atomizer, was performed. The spray stability, cone angle and breakup length were determined. Scaled 3D printed atomizers were tested at equivalent pressures of $0.25,0.5$ and 1 bar. Non-dimensionless parameter, Reynolds number, was preserved for the scaled atomizer. The effect of the surface roughness of the tangential ports, swirl chamber and discharge orifice on atomization was assessed at non-scaled pressure swirl atomizer. The roughness of a swirl chamber was created by corundum and ballotin blasting. The inlet pressures of $2.5,5$ and 10 bar were tested.
\end{abstract}

\section{Introduction}

Pressure swirl atomizers are of pressure atomizers type, pressure energy is converted to the kinetic energy of a liquid spray. The liquid flows into the swirl chamber via three tangential ports. In the swirl chamber, the swirl motion is added to the liquid. The liquid is then discharged through the discharge orifice. These three parts are the most important for the liquid atomization. Pressure swirl atomizers are used in combustion applications. In combustion, the droplet sizes and liquid distribution within the spray are of particular interest. The distribution of droplets within the spray determines the performance of the combustion process, flame structure, amount of emissions created during the combustion process and temperature distribution within the flame [1]. Pressure swirl atomizers are widely tested in Spray laboratory at Brno University of Technology. The modification of spill-line geometry was tested [2,3], the breakup of liquid sheet was studied [4]. The usage of alternative fuels for atomization was investigated [5]. The effect of various geometries of the pressure swirl atomizers has been tested by many other researchers.

The ability to produce the pressure swirl atomizers by $3 \mathrm{D}$ printing technology and the estimation of spray characteristic of the $3 \mathrm{D}$ printed nozzle is assessed in this paper. 3D printing technology belongs to additive technologies, which development started in 1980 's. The development of 3D printing resulted in the ability to print the components

${ }^{*}$ Corresponding author: 182752@vutbr.cz 
with complicated shapes. The advantages of 3D printing are faster production, lower prices and usage of different materials (polymeric materials, metals, biochemical materials). The pressure swirl nozzles are nowadays usually manufactured by CNC machines. The surface roughness of the nozzles, created by $3 \mathrm{D}$ printing, is still poor and surface finish is required. The dimensions of some pressure nozzle parts are challenging and sometimes impossible to replicate, because dimensions of some crucial parts of pressure swirl atomizer are only half millimeter. The scaled pressure swirl atomizer was created and tested.

In literature, only a little attention is devoted to the influence of the surface roughness on atomization quality. In [6] the transition from laminar to turbulent flow regime above the critical Reynolds number is attributed partly to the surface roughness. In [7] a short section is devoted to discuss the influence of the surface roughness of pressure swirl atomizers. The inaccurate surface finish of pressure swirl atomizer resulted in distorted circumferential liquid distribution. In the production of swirl atomizers, the attention is mainly driven to the co-axiality of discharge orifice and swirl chamber. In [8] the notes on the nozzle geometry and surface roughness are presented. The nozzle geometry (surface roughness) has a profound impact on jet characteristics and jet breakup.

As was mentioned before the pressure swirl nozzle is composed of several sections (tangential inlet ports, swirl chamber and discharge orifice). Dimensions of these sections have the largest impact on the spray properties and breakup of the liquid sheet. The influence of misalignments in characteristic dimensions of tangential ports, discharge orifice diameter and swirl chamber diameter are described in [9]. The influence of viscous and frictional loses in pressure swirl atomizers were determined in [10]. The friction coefficient is only a function of a Reynolds number and the effect of wall roughness is not accommodated. Geometrical parameters that influence friction losses were determined. In [11] the friction losses for the swirl chamber are derived. The losses caused by vortex generation and frictional loss are presented. A frictional coefficient is a function of the length of the swirl chamber, the diameter of discharge orifice and drag coefficient. The drag coefficient is only a function of Reynolds number for the hydraulically smooth pipe. The passage is considered as hydraulically smooth if the wall roughness is smaller than $0.7 \%$ of hydraulic diameter of the section. According to [12] the pressure loss coefficient decreases with the increasing ratio of the swirl chamber length to discharge orifice diameter. The angle of the swirl chamber also affects the pressure loss coefficient. In [13] the lack of experimental data on the surface roughness of the atomizers is pointed out. The influence of the surface roughness has been mentioned by many researchers, but detailed experimental study on the influence of surface roughness on the atomization has not been carried out so far.

It is assumed that the roughness of the swirl chamber changes the behaviour of the spray. This change in the behaviour is caused by the surface disturbances that induced instabilities in the fluid flow. In the boundary layer of the liquid flowing through the tangential ports, swirl chamber or discharge orifice, the disturbed surface generates eddies and the boundary layer becomes more turbulent. It is assumed that these eddies then promote and cause a rapid breakup of the liquid sheet. Eddies cause disturbances of the spray and atomizer produces unstable liquid sheet. The energy is dissipated by the surface roughness. In the swirl chamber with large surface roughness, the liquid obtain less tangential velocity. This result in smaller cone angle of the liquid sheet. The main goal of the atomization is to create a stable liquid sheet and spray. The roughness of the surface may have an adverse effect on atomization stability and performance, and it is necessary to investigate this phenomenon. 


\section{Experimental setups}

Two scaled 3D printed nozzles illustrated in Figure 1 were tested. The difference between the nozzles is that one was printed with the rear wall of a swirl chamber (Figure 1. left) and the second is comprised of two parts (swirl chamber and rear wall) separately (Figure 1. right). The final surface roughness of the $3 \mathrm{D}$ printed nozzles is $R a=17.3 \mu \mathrm{m}$. Nozzles were tested in special holder, which provide liquid inlet and rear wall of a swirl chamber for the open nozzles. The instantaneous images for a spray were recorded using high-speed camera, Photron fast cam. The equivalent conditions were set. The atomizers are scaled by the ratio of 3.3 of initial dimensions.
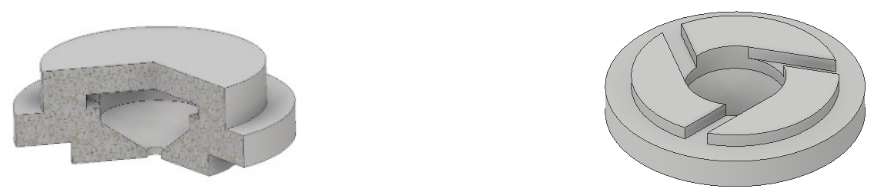

Fig. 1. 3D printed nozzles, closed (left) and open (right).

Three non-scaled atomizers with different surface roughness were tested. The manufactured swirl chamber with $R a=0.872 \mu \mathrm{m}$, swirl chamber artificially created roughness by ballotin blasting with surface roughness $R a=1.661 \mu \mathrm{m}$ and swirl chamber with artificially created roughness by corundum blasting with surface roughness $R a=2.149 \mu \mathrm{m}$. The surface roughness was measured using an optical 3D microscope Alicona Infinitefocus G4. The surface texture of the non-scaled nozzles is illustrated in Figure 2.

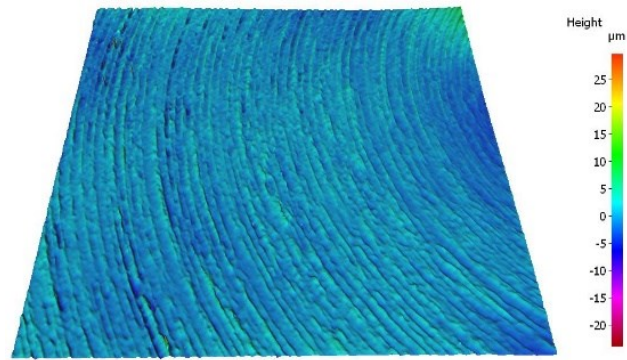

a)

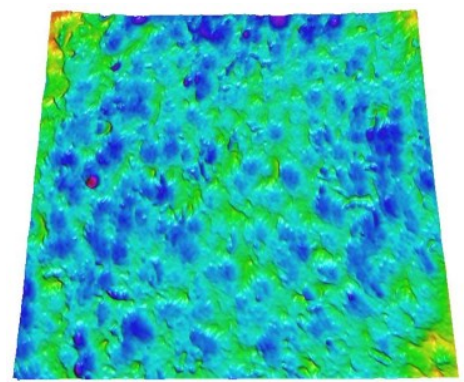

b)

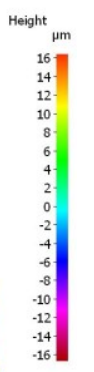

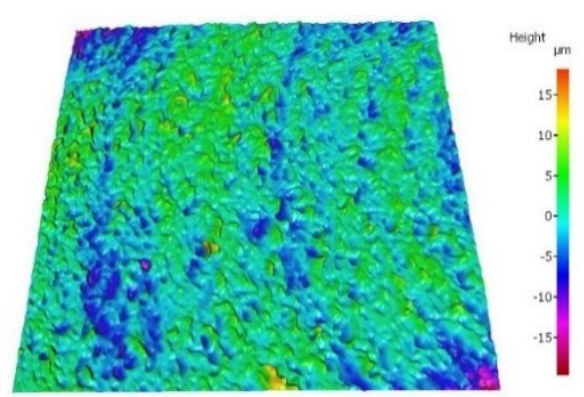

c)

Fig. 2. Surface roughness a) Manufactured nozzle, b) Ballotin blasting, c) Corundum blasting.

The effect of different surface roughness was investigated by the Phase Doppler anemometer (PDA) and by high-speed visualization. The settings of the PDA system are outlined in Table 1. Three different inlet pressures were tested $P_{\text {in }}=2.5,5$ and $10 \mathrm{bar}$. The schematic layout of the PDA experiment is illustrated in Figure 3a. The velocity and droplets diameters were measured in two horizontal planes, $Z=12.5 \mathrm{~mm}$ and $25 \mathrm{~mm}$ from 
the nozzle tip. The schematic layout of the measurement planes with measurement positions is presented in Figure $3 b$.

Table 1. PDA setup.

\begin{tabular}{|c|c|}
\hline & \\
\hline Laser power output & $0.3 \mathrm{~W}$ \\
\hline Wavelength & $514.5 / 488 \mathrm{~nm}$ \\
\hline $\begin{array}{c}\text { Focal length of } \\
\text { transmitting optics }\end{array}$ & $500 \mathrm{~mm}$ \\
\hline $\begin{array}{c}\text { Focal length of receiving } \\
\text { optics }\end{array}$ & $500 \mathrm{~mm}$ \\
\hline Scattering angle & $69^{\circ}$ \\
\hline Mask & $\mathrm{B}$ \\
\hline Spatial filter & $0.1 \mathrm{~mm}$ \\
\hline Sensitivity & $850 \mathrm{~V} / 950 \mathrm{~V}$ \\
\hline SNR & $0 \mathrm{~dB}$ \\
\hline Signal gain & $10 \mathrm{~dB}$ \\
\hline Level validation ratio & 8 \\
\hline
\end{tabular}

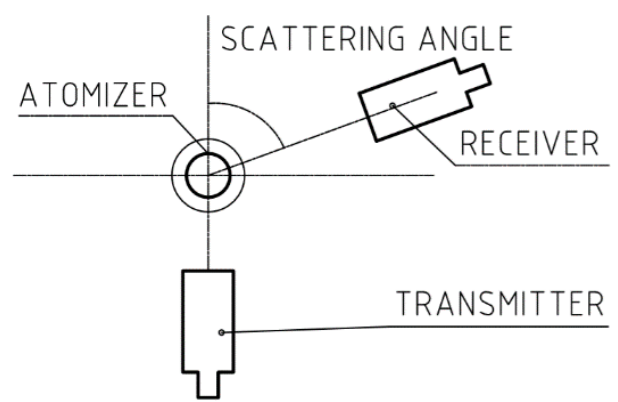

a)

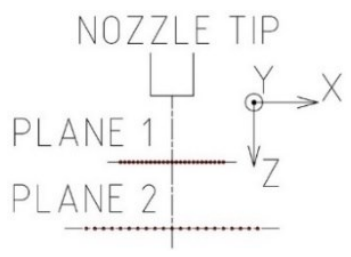

b)

Fig. 3. PDA setup.

\section{Results and discussion}

In this section results obtained using PDA measurement system and high-speed camera are presented. The influence of surface roughness on the velocity, droplet distribution, spray cone angle and breakup length is determined. The spray created by scaled 3D printed nozzles is investigated and atomization characteristics are discussed. The Reynold number for tangential ports and the relative roughness are outlined in Table 2. The Reynolds number for swirl chamber and discharge orifice is not presented, because the flow nature is very complicated and computation is not straight forward process. Relative roughness is defined as $R a$ divided by hydraulic diameter of the section. 
Table 2. The Reynolds numbers at the inlet ports and relative roughness

\begin{tabular}{|c|c|c|c|c|c|c|}
\hline & \multicolumn{3}{|c|}{ Reynolds number [-] } & \multicolumn{3}{c|}{ Relative roughness [-] } \\
\hline Regime [bar] & 2.5 & 5 & 10 & 2.5 & 5 & 10 \\
\hline Manufactured & 880 & 1179 & 1661 & 0.0018 & 0.0018 & 0.0018 \\
\hline Ballotin blasting & 890 & 1181 & 1644 & 0.0034 & 0.0034 & 0.0034 \\
\hline Corundum blasting & 883 & 1177 & 1631 & 0.0044 & 0.0044 & 0.0044 \\
\hline Regime [bar] & 0.25 & 0.5 & 1 & 0.25 & 0.5 & 1 \\
\hline 3D printed, closed & 902 & 1245 & 1784 & 0.0110 & 0.0110 & 0.0110 \\
\hline 3D printed, open & 944 & 1294 & 1777 & 0.0110 & 0.0110 & 0.0110 \\
\hline
\end{tabular}

\subsection{Surface roughness}

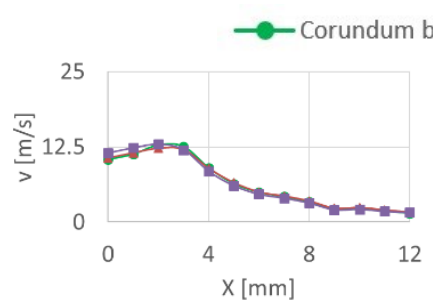

a)

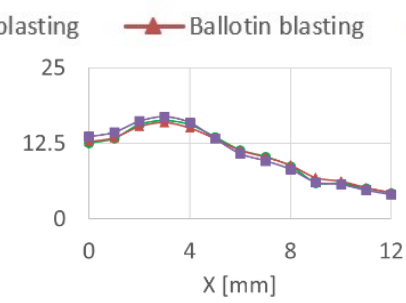

b)

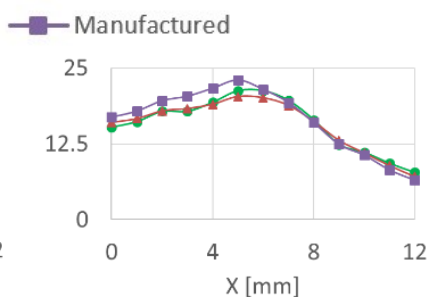

c)

Fig. 4. Axial velocity, $Z=12.5 \mathrm{~mm}$, a) 2.5 bar, b) 5 bar, c) 10 bar.

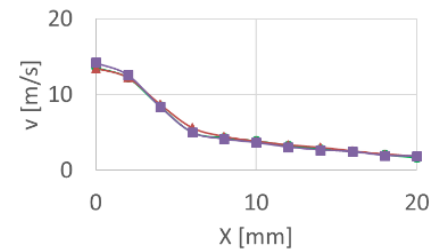

a)

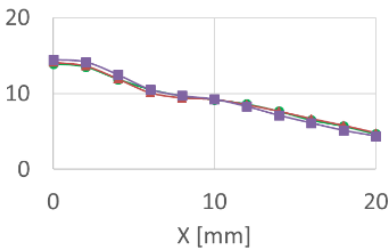

b)

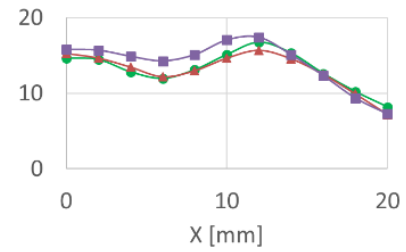

c)

Fig. 5. Axial velocity, $Z=25 \mathrm{~mm}$, a) $2.5 \mathrm{bar}$, b) 5 bar, c) 10 bar.

In Figure 4 and 5 the axial velocity for two measurement planes and different inlet pressures is illustrated. The surface roughness has no impact on the axial velocity of a spray. The change of axial velocity with the change of inlet pressure is apparent. In Figure 6 and 7 , the $D_{32}$ is illustrated for two measurement planes and different inlet pressures. The $D_{32}$ (also known as a Sauter mean diameter) is important characteristics of a spray for combustion application. It is the ratio of the volume of the particle to the particle surface. $D_{32}$ is defined by equation 1 . Where $N_{i}$ is the number of droplets and $D_{i}$ is the droplet diameter.

$$
D_{32}=\sum_{i} N_{i} D_{i}^{3} / \sum_{i} N_{i} D_{i}^{2}
$$

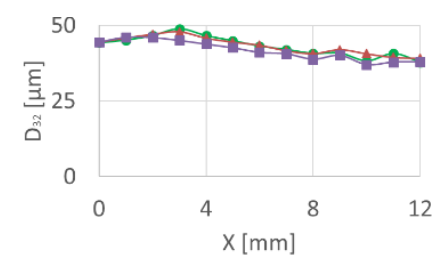

a)

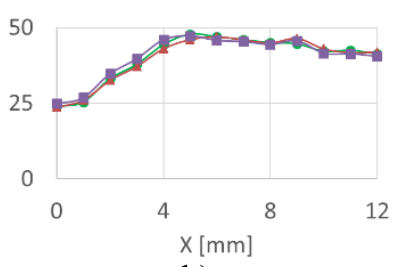

b)

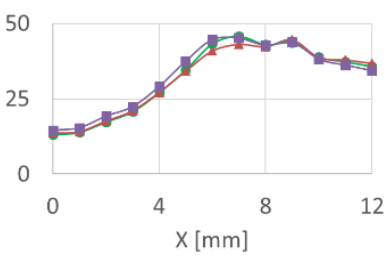

c)

Fig. 6. Profile of $D_{32}, Z=12.5 \mathrm{~mm}$, a) 2.5 bar, b) 5 bar, c) 10 bar. 


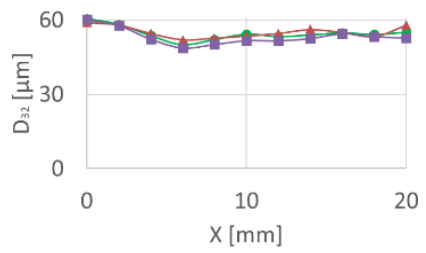

a)

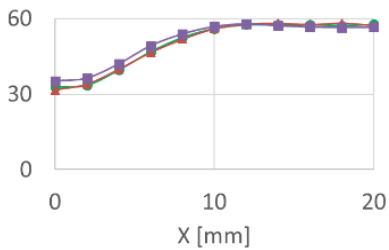

b)

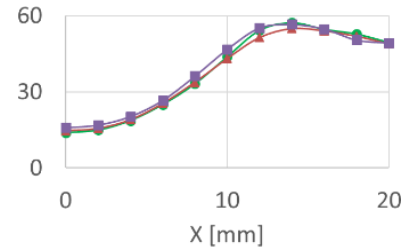

c)

Fig. 7. Profile of $D_{32}, Z=25 \mathrm{~mm}$, a) 2.5 bar, b) 5 bar, c) 10 bar.

The surface roughness influences the distribution of liquid within the spray. The liquid distribution is presented in Figure 8 and 9.

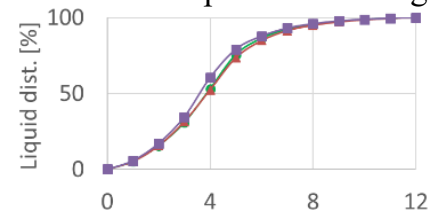

a)

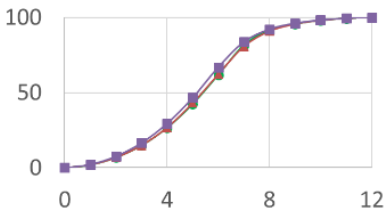

b)

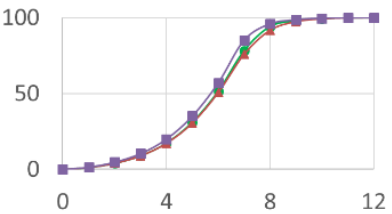

c)

Fig. 8. Liquid distribution, $Z=12.5 \mathrm{~mm}$, a) $2.5 \mathrm{bar}$, b) 5 bar, c) 10 bar.

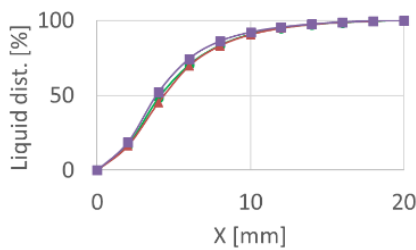

a)

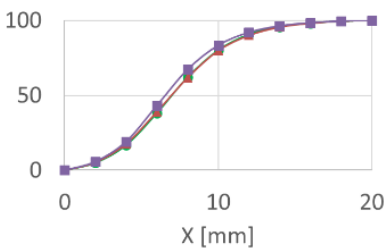

b)

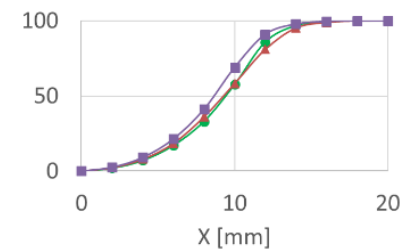

c)

Fig. 9. Liquid distribution, $Z=25 \mathrm{~mm}$, a) $2.5 \mathrm{bar}$, b) 5 bar, c) 10 bar.

The spray cone angle and breakup distance were derived from set of 3000 instantaneous images of the spray illustrated in Figure 10.
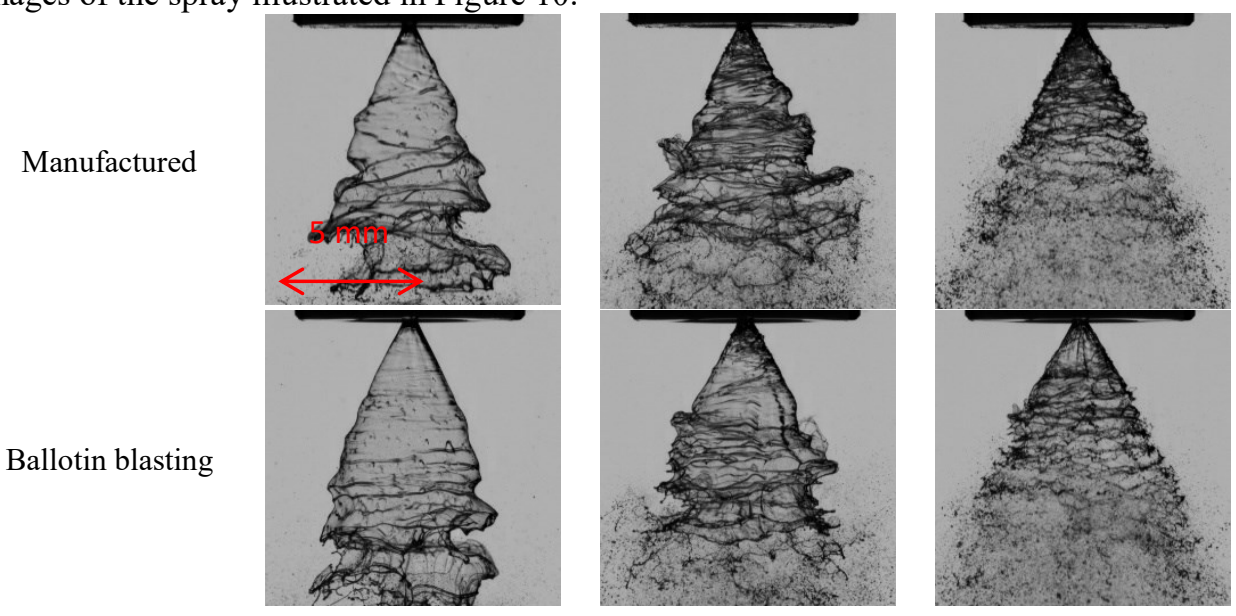


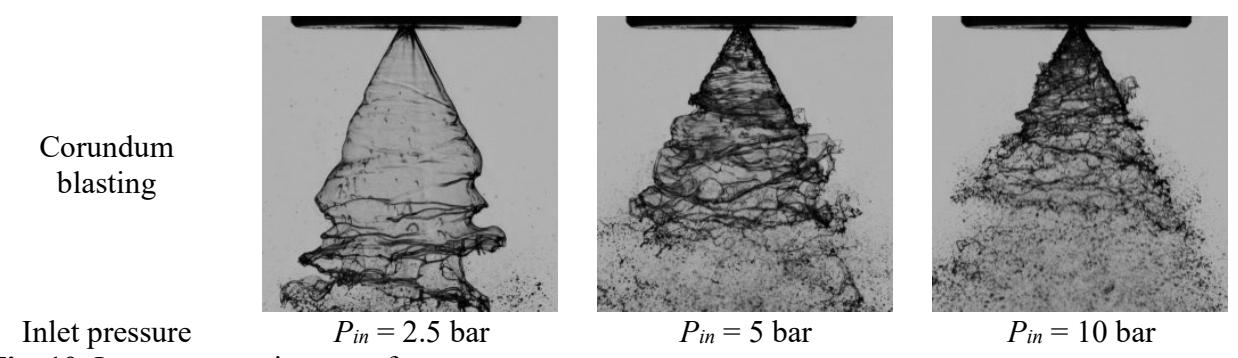

Fig. 10. Instantaneous images of a spray.

The cone angle is presented in Figure 11. The standard mean deviation is illustrated for each regime. From Figure 11, the difference in cone angle is not recognized. The breakup length for different swirl chambers and different inlet pressures is presented in Figure 12.

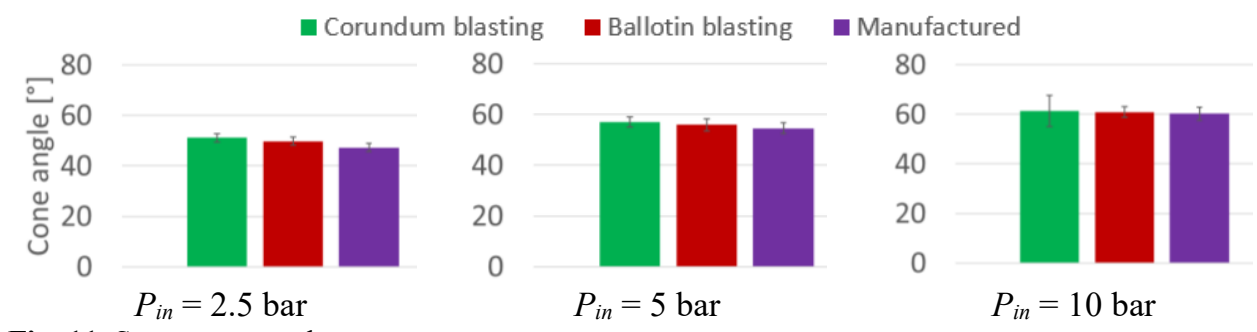

Fig. 11. Spray cone angle.

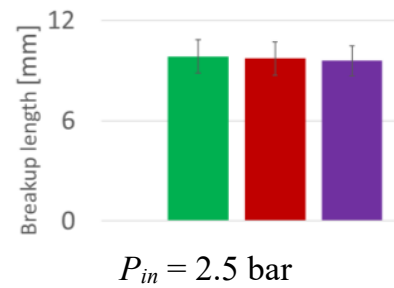

12

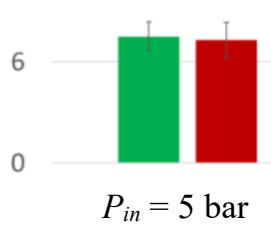

12
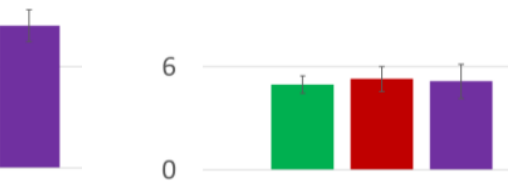

$P_{\text {in }}=10$ bar

Fig. 12. Breakup length.

Surface roughness can affect the discharge coefficient $(C D)$. The discharge coefficient is defined as the ratio of measured mass flow rate at the discharge orifice to mass flow rate of an ideal nozzle. The discharge coefficient for different surface roughness is illustrated in Figure 13.

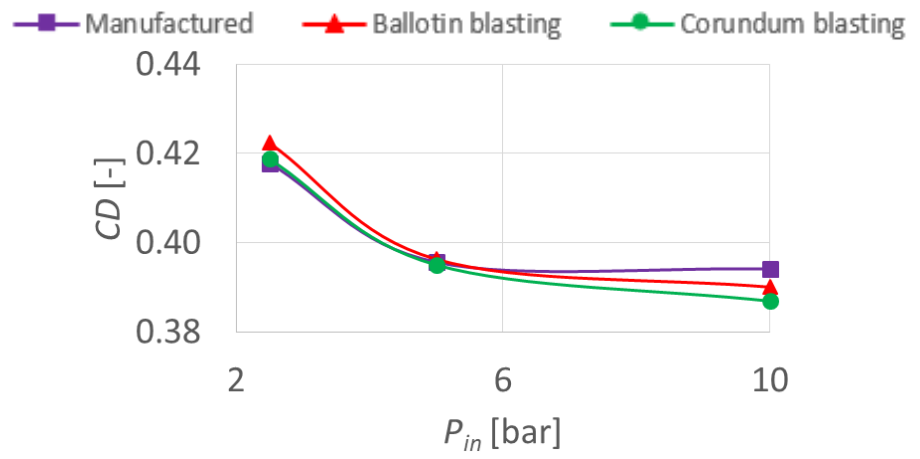

Fig. 13. Discharge coefficient for different surface roughness. 
Discharge coefficient decreases with increase of inlet pressure. Largest differences are observed for 10 bar. The difference lies in span of measurement accuracy.

\subsection{D printed nozzles}

Examined atomizers are illustrated in Figure 1. The equivalent inlet pressures were 0.25, 0.5 and 1 bar. The surface of the printed atomizers was not machined after the 3D printing. The shape of the spray is illustrated in Figure 14.

Closed design

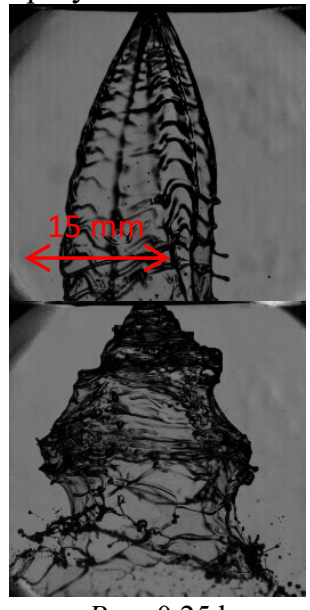

Inlet pressure

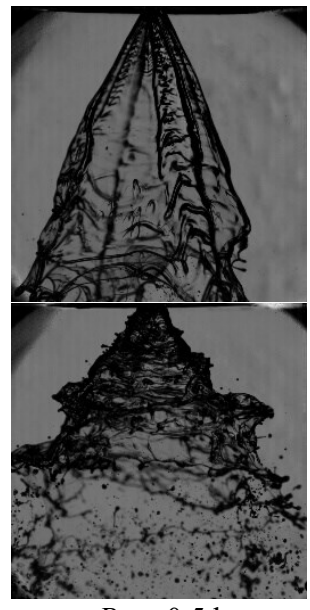

$P_{\text {in }}=0.5$ bar

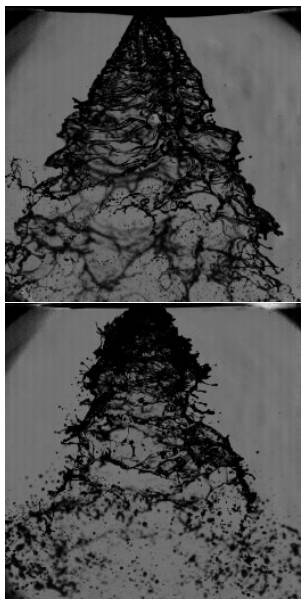

$P_{i n}=1 \mathrm{bar}$

Fig. 14. Instantaneous images of a spray created by $3 \mathrm{D}$ printed nozzles.

The spray is unstable with a great number of surface waves. The spray created by closed nozzle is not symmetrical, streaks are created during 0.25 and 0.5 bar regimes. The instabilities of the sprays are created by the swirl chamber, tangential ports or discharge orifice wall roughness, the imperfection in the discharge orifice diameter or can be caused by the inappropriate sharpness of the edges.

The cone angle and the breakup length for 3D printed nozzles are represented in Figure 15 and 16.

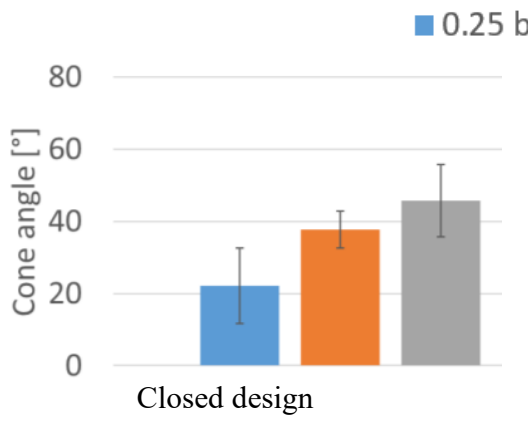

Fig. 15. Cone angle of the $3 \mathrm{D}$ printed nozzles.

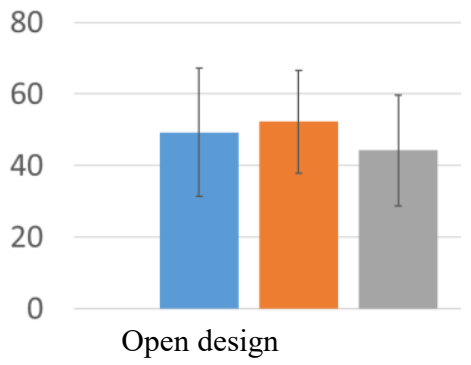

According to the pressure swirl nozzles theory, the cone angle is expected to increase with the inlet pressures increase. The closed atomizer design obey this trend. The open atomizer do not behave according to the pressure swirl theory. The spray cone angle for $1 \mathrm{bar}$ regime is narrower than for the inlet pressure of 0.25 and 0.5 bar. This can be caused by the 
transition of the flow to the turbulent regime, where surface roughness plays an important role.

The breakup length for these two designs and different pressure regimes is illustrated in Figure 16. The spray produced by the open nozzle is more unstable than the spray produced by the closed nozzle. The breakup length is reduced for the open design. Discharge coefficient for 3D printed nozzles is illustrated in Figure 17.
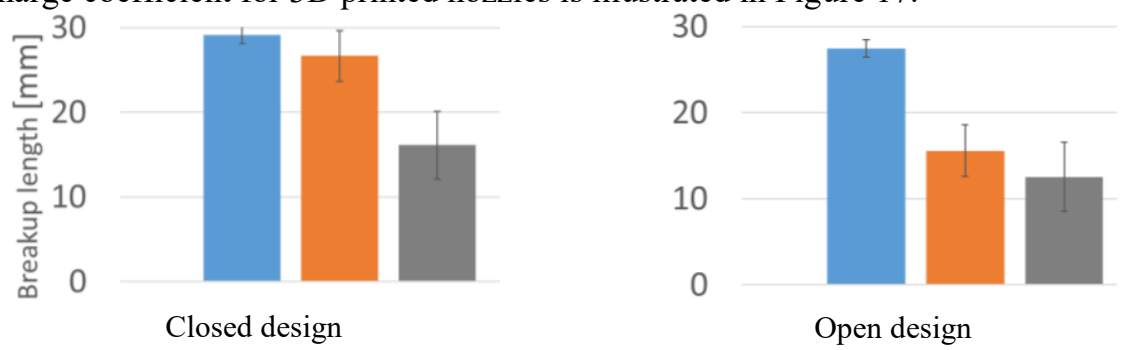

Fig. 16. Breakup length of the $3 \mathrm{D}$ printed nozzles.

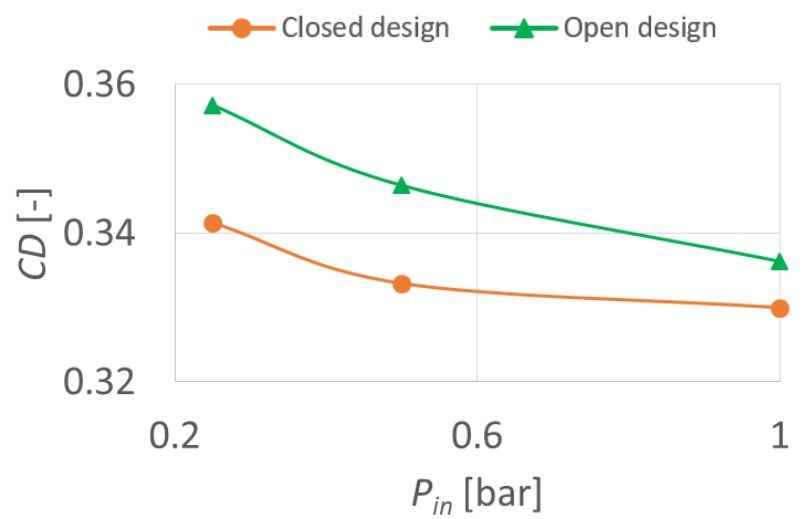

Fig. 17. Discharge coefficient for 3D printed nozzles.

The larger difference is observed in Discharge coefficient of 3D printed nozzles than for nozzles with different surface roughness (Figure 12). This behaviour can be explained by the poorly manufactured dimensions of inlet ports, swirl chamber or discharge orifice of 3D printed nozzles or by the changed shape of main parts of the nozzles.

From Figure 4 to Figure 13, the influence of the nozzle surface roughness is negligible. In the swirl chamber, with relatively large diameter, the laminar flow is present. In the laminar region, the friction coefficient is independent of the wall roughness. The roughness of the discharge orifice and tangential ports plays more important role in the atomization process. Moody diagram is determined for the flow in the pipe. The use of Moody diagram for the flow in tangential ports and swirling flow in the discharge orifice can be misleading.

\section{Conclusions}

In this study nozzles with different surface roughness were tested. The investigated range of surface roughness has no influence on velocity, droplet behaviour and discharge coefficient. All differences lies within the measurement accuracy of the measurement system. The two $3 \mathrm{D}$ printed scaled atomizers were investigated by high speed visualization. The created spray is very unstable with lots of surface waves and streak are formed for some regimes. The 3D printed nozzle, referred here as an open nozzle, exhibits different behaviour for inlet pressure 1 bar (Figure 14). This can be caused by some large imperfection on the surface of the 
tangential ports, swirl chamber or discharge orifice, which causes the transition to the turbulent flow. This nozzle works in transition regime near the fully developed turbulent regime. The Reynolds numbers and relative roughness in Table 2 lies within a small area in the Moody Diagram and behaviour of the flow is similar for each case. The flow is in the transition zone. The larger extend of surface roughness and flow Reynolds number is needed to investigate the influence of the surface roughness on the atomization quality in detail.

Acknowledgement: The authors acknowledge the financial support from the project No. 18-15839S funded by the Czech Science Foundation

\section{References}

1. J. A. Bossard, R. E. Peck, Symp. Int. Combust. 26, 1 (1996)

2. M. Malý, O. Cejpek, M. Sapík, V. Ondráček, G. Wigley, J. Jedelský, EXP THERM FLUID SCI, 120 (2021)

3. M. Malý, M. Sapík, O. Cejpek, G. Wigley, J. Katolický, J. Jedelský, EXP THERM FLUID SCI, 106 (2019)

4. M. Malý, J. Jedelský, J. Sláma, L. Janáčková, M. Sapík, G. Wigley, M. Jícha, Int. J. Heat Mass Transf., 123 (2018)

5. M. Malý, L. Janáčková, J. Jedelský, M. Jícha, AEANMIFMAE-2016 (2016)

6. A. H. Lefebvre, V. G. McDonnel, Atomization and sprays, CRC Press (2017)

7. L. Bayvel, Z. Orzechowski, LIQUID ATOMIZATION, Taylor \& Francis (1993)

8. H. G. Merkus, G. M. H. Meesters, Production, Handling and Characterization of Particulate Materials, Springer

9. J. Jedelský, M. Malý, M. Jícha, J. Sláma, G. Wigley, J PROPUL POWER (to be published)

10. M. Rashad, H. Yong, Ch. Bin, IBCAST (2016)

11. V. Bazarov, Liquid Rocket Thrust Chambers (2004)

12. V.A. Borodin, Yu. F. Dityakin, Atomization of Liquids (1968)

13. J. J. Chinn, The Internal Flow Physics of Swirl Atomizer Nozzles, 229 (1996) 